\title{
RETRACTED ARTICLE: Floristic and ethnoecological diversity in various habitats of a semi-arid area in the Chakwal district (Pakistan), with special emphasis on medicinal plants
}

\author{
Mehwish Jamil Noor • Mushtaq Ahmad • Muhammad Zafar • \\ Maliha Sarfraz • Ismail Yusoff • Yatimah Alias · Muhammad Aqeel Ashraf
}

Received: 15 April 2014/ Accepted: 17 July 2014/Published online: 28 August 2014

(C) Springer Science+Business Media Dordrecht 2014

This article has been retracted by Editors-in-Chief. After a thorough investigation carried out according to the Committee on Publication Ethics guidelines, we have strong reason to believe that the peer review process was compromised.

Electronic supplementary material The online version of this article (doi:10.1007/s11258-014-0384-1) contains supplementary material, which is available to authorized users.

\section{J. Noor}

Department of Environmental Sciences, Fatima Jinnah Women University, The Mall, Rawalpindi 46000,

Pakistan

M. Ahmad - M. Zafar

Department of Plant Sciences, Quaid-i-Azam University,

Islamabad 45320, Pakistan

M. Sarfraz

Department Physiology \& Pharmacology, University of Agriculture, Faisalabad 38040, Pakistan
The online version of this article contains the full text of the retracted article as electronic supplementary material.

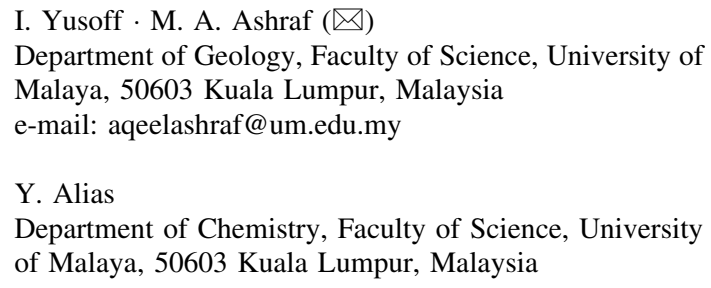

